\title{
Analisis Kepuasan Konsumen pada Produk Waralaba Teh cap Poci di Kecamatan Denpasar Selatan Kota Denpasar
}

\author{
EDEN POSTER LALALA, I KETUT SUAMBA, \\ I DEWA AYU SRI YUDHARI
}

\author{
Program Studi Agribisnis Fakultas Pertanian Universitas Udayana \\ Jl. PB Sudirman Denpasar 80232 \\ Email: eden.poster18@yahoo.co.id \\ suamba_unud@yahoo.co.id
}

\begin{abstract}
Analysis of Customer Satisfaction on Franchise Products of Cap Poci Tea in the Sub-District of Southern Denpasar of Denpasar City.
\end{abstract}

Competition is common and cannot be avoided, not least in the franchise tea of cap poci. Employers of franchise tea of cap poci must continue to innovate or to improve the shortcomings so that consumers do not run into other products. Consumer behavior may help explain how consumers obtain satisfaction. This study aimed to determine the level of customer satisfaction on the franchise tea of cap poci and what actions should be conducted based on matrix of Importance-Performance. The location of research was in South Denpasar Sub-District as having the greatest potential consumers. The total sample of 30 respondents and sampling was conducted by accidental sampling. The data collection includes quantitative data and qualitative data derived from primary and secondary data. Data collection methods used were interviews and literature studies. Methods of data analysis using descriptive analysis, Importance-Performance Analysis and Custumer satisfication Index. Based on the research results, the value or rate of CSI calculation was 69.34\%. The CSI Value of the franchise iced tea products of tea cap poci meets the criteria of satisfied. But still need increased performance. Based on the ImportancePerformance Matrix, the product attributes that need to be improved are: hygiene, price, and taste attributes.

Keywords: customer, satisfaction, franchise, importance-performance analysis

\section{Pendahuluan}

\subsection{Latar Belakang}

Teh cap Poci merupakan salah satu usaha waralaba yang ada dan berkembang untuk memenuhi kebutuhan masyarakat. Hingga kini ribuan merek waralaba dan ribuan gerai yang tersebar di seluruh daerah di Indonesia. Tercatat oleh Asosiasi Franchise Indonesia bahwa terdapat 1.300 merek waralaba dan 3.000 gerai pada tahun 2010 dan meningkat pada tahun 2011 sekitar 1.700 merek dan 36.000 gerai/outlet, dan dapat dipastikan akan meningkat terus setiap tahunnya. Perputaran 
uang mencapai 114 triliun pada tahun 2010 dan 214 triliun pada tahun 2011 (Purwantini,2014).

Seiring berjalannya waktu banyak saingan yang bermunculan, oleh karena itu para pengusaha waralaba Teh cap Poci harus terus berinovasi ataupun memperbaiki kekurangan secepat mungkin agar konsumen tidak lari ke produk lain.Perilaku konsumen dapat membantu menjelaskan bagaimana konsumen memperoleh kepuasan dan dari kepuasan tersebut konsumen menjadi loyal terhadap suatu produk tertentu yang dianggap dapat mengakomodasi kebutuhannya. Sumarwan (2004), menyatakan bahwa dengan memahami perilaku konsumen maka dapat memperkirakan bagaimana konsumen mengambil keputusan konsumsi dan dapat memperkirakan reaksi konsumen sehingga dapat mempengaruhi pilihan konsumen agar memilih produk dan merek tertentu.

Tingkat kepuasan pelanggan atau konsumen sangat tergantung pada kualitas atau mutu suatu produk yang meliputi barang dan jasa. Jika kualitas produk yang ditawarkan sama atau lebih besar dari harapan konsumen maka kepuasan akan terjadi, sebaliknya jika kualitas yang ditawarkan lebih rendah dari harapan maka konsumen akan merasa dikecewakan/tidak puas. Kepuasan yang didapat konsumen dapat menyebabkan terjadinya pembelian ulang bahkan konsumen dapat menjadi loyal (Supranto, 2006). Oleh karena itu, penting bagi pengusaha waralaba Teh cap Poci untuk mengetahui hal-hal yang dapat mempengaruhi kepuasan pelanggan. Informasi mengenai perilaku konsumen sangat diperlukan untuk membuat keputusan yang tepat dan bukan sekedar input, melainkan sudah menjadi aset dan alat pemasaran. Informasi mengenai perilaku konsumen dengan perubahan pasar dan industri yang cepat sangat penting bagi perusahaan, sehingga hanya perusahaan yang memiliki informasilah yang dapat menyesuaikan rencana.

Teh cap Poci sudah sangat berkembang di kota-kota besar seperti Jakarta, Surabaya, Denpasar dan kota besar lainnya di seluruh Indonesia untuk memenuhi pemintaan konsumen produk es teh dari waralaba Teh cap Poci. Kecamatan Denpasar Selatan merupakan Kecamatan yang memiliki jumlah penduduk tertinggimaka dapat dikatakan bahwa wilayah Kecamatan Denpasar Selatan memiliki konsumen potensial terbanyak di Kota Denpasar. Hal inilah yang menarik bagi penulis untuk melakukan penelitian mengenai Analisis Tingkat Kepuasan Konsumen Produk pada Waralaba "Teh cap Poci" di Kecamatan Denpasar Selatan, Kota Denpasar.

\subsection{Tujuan Penelitian}

Penelitian ini bertujuan untuk menganalisis kepuasan konsumen dan mengetahui strategi apa atau tindakan yang harus dilakukan untuk meningkatkan kepuasan konsumen produk waralaba Teh cap Poci di Kecamatan Denpasar Selatan, Kota Denpasar. 


\section{Metode Penelitian}

\subsection{Lokasi dan Waktu Penelitian}

Penentuan lokasi penelitian di Kecamatan Denpasar Selatan karena dianggap memiliki konsumen potensial terbesar dengan jumlah penduduk terbesar di Kota Denpasar. Pengumpulan data dan pengolahan data dilaksanakan mulai bulan November 2015 sampai selesai.

\subsection{Populasi dan Responden Penelitian, Jenis dan Sumber Data}

Menurut Sugiyono (2010), populasi adalah suatu wilayah generalisasi yang dimana terdiri dari objek dan subjek yang mempunyai kuantitas dan karakteristik tertentu yang ditetapkam oleh peneliti untuk dipelajari, kemudian ditarik suatu kesimpulan. Populasi dalam penelitian ini yaitu seluruh konsumen produk es teh waralaba Teh cap Poci di Kecamatan Denpasar Selatan produk waralaba Teh cap Poci. Jumlah populasi penelitian ini tidak diketahui secara jelas. Sampel adalah sebagian atau wakil dari populasi yang menjadi sumber data yang sebenarnya dalm suatu penulisan dimana sebagian individu yang diteliti tersebut sebagai contoh (Nawawi,1997). Responden adalah orang-orang yang merespon atau menjawab pertanyaan tertulis ataupun lisan (Arikunto,2002). Jumlah sampel atau responden dalam penelitian ini ditentukan secara sengaja yaitu sebanyak 30 orang responden. Jumlah ini dianggap sudah dapat mewakili populasi.

Teknik penarikan sampel atau responden yang digunakan dalam penelitian ini adalah dengan metode accidental sampling. Accidental sampling adalah teknik sampling dengan mempertimbangkan kemudahan. Sampel atau responden ditemukan secara kebetulan artinya siapa saja yang bertemu dengan peneliti dan cocok sebagai responden dapat dijadikan sampel. Responden yang dimaksudkan adalah yang sudah pernah membeli dan mengkonsumsi produk Teh cap Poci.

\subsection{Metode Pengumpulan Data, Variabel Penelitian, dan Metode Analisis Data}

Pengumpulan data dilakukan dengan cara wawancara terhadap responden dan studi literatur. Variabel dalam penelitian ini mencakup tingkat kepentingan (importance) dan tingkat kinerja (performance) menurut penilaian responden. Metode analisis data yang digunakan dalam penelitian ini adalah deskriptif, Importance Performance Analysis (IPA) dan Customer Satisfaction Index (CSI).

\section{Pembahasan}

\subsection{Karakteristik Responden}

Karakteristik responden adalah gambaran mengenai identitas responden dalam penelitian ini. Karakteristik responden didalam penelitian ini meliputi aspek demografi dan aspek pembelian, yaitu sebagai berikut: 


\subsubsection{Aspek demografi}

Aspek demografi terdiri dari jenis kelamin, usia, pekerjaan, pengeluaran per bulan, dan tingkat pendidikan, yang dijelaskan sebagai berikut:

a. Karakteristik responden berdasarkan jenis kelamin menunjukkan jumlah responden hampir sama yaitu pria sebanyak 17 responden dan wanita sebanyak 13 responden. Artinya baik pria dan wanita sama-sama meminati produk waralaba Teh cap Poci. Produk waralaba Teh cap Poci memang boleh dan baik dikonsumsi oleh siapa saja baik pria atau wanita.

b. Karakteristik responden berdasarkan umur atau usia menunjukkan jumlah responden didominasi oleh konsumen yang berusia produktif atau yang memiliki aktivitas yang cukup padat. Pada kelompok usia 18-25 tahun sebanyak 20 responden dan kelompok usia 26-35 tahun sebanyak tujuh responden. Artinya produk waralaba Teh cap Poci yaitu orang-orang yang sibuk sehingga tidak sempat membuat sendiri sehingga membeli minuman instan dalam kemasan khususnya produk waralaba es Teh cap Poci.

c. Karakteristik responden berdasarkan pekerjaan menunjukkan jumlah responden didominasi oleh konsumen yang memiliki aktifitas padat dan kesibukan yaitu Pelajar/Mahasiswa sebanyak 15 responden, karyawan swasta, serta PNS/TNI/POLRI masing-masing sebanyak tujuh dan dua responden. Artinya ratarata konsumen memiliki kesibukan dan tidak sempat membuat minuman sendiri di rumah atau kos-kosan.

d. Karakteristik responden berdasarkan pengeluaran menunjukan bahwa responden konsumen produk waralaba Teh cap Poci yaitu dari kalangan menengah ke bawah. Jumlah responden dengan rata-rata pengeluaran perbulan dari Rp.1.000.000-Rp2.000.000 mencapai sebanyak 15 responden yaitu setengah dari jumlah responden, diikuti oleh responden dengan rata-rata pengeluaran Rp.2.000.001-Rp.3.000.000 sebanyak sembilan responden.

e. Karakteristik berdasarkan tingkat pendidikan, menunjukkan jumlah responden terbanyak yaitu responden dengan pendidikan terakhir SMA/SMK yang sedang melanjutkan ke perguruan tinggi atau yang sudah bekerja dengan jumlah sebanyak 16 responden, dan diikuti oleh responden dengan tingkat pendidikan S1 sebanyak tujuh responden.

\subsubsection{Aspek pembelian}

Aspek pembelian meliputi sumber informasi yang didapat responden tentang Teh cap Poci, keputusan pembelian Teh cap Poci dan pemberi pengaruh pada responden dalam pembelian produk Teh cap Poci.

a. Karakteristik responden berdasarkan sumber informasi tentang produk waralaba Teh cap Poci menunjukkan mayoritas responden mendapatkan informasi tentang waralaba Teh cap Poci yaitu dari relasi yaitu sebanyak 17 responden dan dari media media sosial sebanyak delapan responden sedangkan iklan baik media cetak maupun media elektronik hampir tidak ada. Artinya, perusahaan masih kurang 
baik dalam melakukan promosi berupa iklan baik elektronik maupun cetak, untuk memperkenalkan produk dan sekaligus menjaring konsumen untuk mengkonsumsi produk es Teh cap Poci.

b. Karakteristik responden berdasarkan keputusan dalam pembelian produk waralaba Teh cap Poci menunjukkan responden yang membeli tanpa perencanaan sebanyak 22 responden dan yang membeli dengan merencanakan terlebih dahulu sebanyak delapan responden. Artinya, mayoritas konsumen membeli es Teh cap Poci tidak disengaja atau tidak direncanakan. Hal ini dikarenakan konsumen yang berasal dari kalangan menengah ke bawah, yang menunggu apabila ada sisa pengeluaran lebih yang cukup untuk membeli minuman instan dalam kemasan seperti es Teh cap Poci.

c. Karakteristik responden berdasarkan pemberi pengaruh dalam pembelian produk waralaba Teh cap Poci menunjukkan jumlah responden dengan keinginan diri sendiri dalam membeli dan mengkonsumsi produk es Teh cap Poci sebanyak 15 responden dan diikuti oleh responden yang membeli serta mengkonsumsi produk es Teh cap Poci dipengaruhi oleh teman sebanyak 10 responden.

\subsection{Importance-Performance Analysis}

Penelitian ini menggunakan metode importance-performance analysis untuk melihat tingkat kepentingan yaitu yang diharapkan konsumen dan tingkat kinerja yaitu yang dirasakan konsumen.Menurut Kotler (1997) kepuasan pelanggan adalah "... a person's feeling of pleasure or disappointment resulting from comparing a product's received performance (or outcome) in relations to person's expectation"perasaan senang atau kecewa seseorang sebagai hasil dari perbandingan antara prestasi atau produk yang dirasakan dan yang diharapkannya.Selanjutnya Kotler (2000) menyebutkan kepuasan adalah perasaan senang atau kecewa seseorang yang berasal dari perbandingan antara kesannya terhadap kinerja (hasil) sesuatu produk dengan harapannya.

\subsubsection{Penilaian responden}

Penilaian ini terdiri dari penilaian terhadap tingkat kepentingan dan tingkat kinerja. Responden memberikan penilaian mulai dari skor 1 sangat tidak penting hingga 5 sangat penting yaitu untuk menilai tingkat kepentingan atribut produk es teh waralaba Teh cap Poci. Hasil tabulasi perhitungan rata-rata penilaian responden terhadap tingkat kepentingan atribut dapat dilihat pada tabel berikut. 
Tabel 1.

Jumlah dan Rata-rata Penilaian Responden terhadap Tingkat Kepentingan Atribut

\begin{tabular}{lrc}
\hline \multicolumn{1}{c}{ Atribut } & Total & Rata-rata \\
\hline Harga & 132 & 4,40 \\
Desain kemasan & 77 & 2,57 \\
Rasa & 127 & 4,23 \\
Aroma & 92 & 3,07 \\
Pemenuhan manfaat & 128 & 4,27 \\
Volume & 111 & 3,70 \\
Kebersihan & 136 & 4,53 \\
Kepopuleran merek & 75 & 2,50 \\
Kepraktisan & 108 & 3,60 \\
Kemudahan memperoleh & 122 & 4,07 \\
\hline Sum
\end{tabular}

Sumber: Data Primer, 2015

Tabel diatas menunjukkan bahwa atribut kebersihan memperoleh total skor kepentingan tertinggi, diikuti oleh atribut harga, pemenuhan manfaat, rasa. Artinya responden menganggap bahwa keempat atribut teratas ini penting, sedangkan atribut kepopuleran merek dan desain kemasan memperoleh peringkat terendah dan dianggap kurang penting, hal ini dikarenakan responden tidak terlalu peduli dengan kepopuleran merek dan desain kemasan.

Penilaian tingkat kinerja yang dirasakan oleh responden terhadap atribut produk es teh waralaba Teh cap Poci responden diberikan skor 1 "sangat tidak baik" hingga skor 5 "sangat baik". Hasil tabulasi perhitungan rata-rata penilaian responden terhadap tingkat kinerja atribut dapat dilihat pada tabel berikut.

Tabel 2.

Jumlah dan Rata-rata Penilaian Responden terhadap Tingkat Kinerja Atribut

\begin{tabular}{lrc}
\hline \multicolumn{1}{c}{ Atribut } & Total & Rata-rata \\
\hline Harga & 93 & 3,10 \\
Desain kemasan & 117 & 3,90 \\
Rasa & 96 & 3,20 \\
Aroma & 86 & 2,87 \\
Pemenuhan manfaat & 114 & 3,80 \\
Volume & 116 & 3,87 \\
Kebersihan & 72 & 2,40 \\
Kepopuleran merek & 114 & 3,80 \\
Kepraktisan & 123 & 4,10 \\
Kemudahan memperoleh & 121 & 4,03 \\
\hline Sumber: Data Pim, 2015 & &
\end{tabular}

Sumber: Data Primer, 2015 
Tabel di atas menjelaskan bahwa responden masih merasa kurang puas dengan beberapa atribut yaitu kebersihan, aroma, harga dan rasa. Keempat atribut ini merupakan yang terendah untuk penilaian tingkat kepuasan atribut sedangkan atribut dengan total skor kepuasan tertinggi adalah atribut kepraktisan dan kemudahan memperoleh.

\subsubsection{Customer satisfication index}

Customer satisfaction index (CSI) merupakan suatu ukuran keterkaitan konsumen kepada suatu merek. Ukuran ini mampu memberikan gambaran tentang kemungkinan seorang pelanggan beralih ke merek produk lain, terutama jika pada merek tersebut didapati adanya perubahan, baik mengenai harga maupun atribut lainnya (Rangkuti,2006).Metode ini digunakan untuk mengukur indeks kepuasan konsumen (Indeks Satisfaction) dari tingkat kepentingan (importance) dan tingkat kinerja (performance) yang berguna untuk pengembangan program pemasaran yang mempengaruhi kepuasan pelanggan (Supranto, 2006).Tanpa adanya Customer Satisfaction Index tidak mungkin Manajer dapat menentukan tujuan dalam peningkatan kepuasan konsumen (Irawan, 2004). Berikut tabel perhitungan CSI Produk es teh waralaba Teh cap Poci.

Tabel 3.

Perhitungan Customer Satisfication Indeks (CSI)

Produk Es Teh Waralaba Teh cap Poci

\begin{tabular}{lcccc}
\hline \multicolumn{1}{c}{ Atribut } & RSP & WF & RSK & WS \\
\hline Harga & 4,40 & 0,119 & 3,10 & 0,369 \\
Desain Kemasan & 2,57 & 0,069 & 3,90 & 0,271 \\
Rasa & 4,23 & 0,115 & 3,20 & 0,367 \\
Aroma & 3,07 & 0,083 & 2,87 & 0,238 \\
Pemenuhan Manfaat & 4,27 & 0,116 & 3,80 & 0,439 \\
Volume & 3,70 & 0,100 & 3,87 & 0,387 \\
Kebersihan & 4,53 & 0,123 & 2,40 & 0,295 \\
Kepopuleran Merek & 2,50 & 0,068 & 3,80 & 0,257 \\
Kepraktisan & 3,60 & 0,097 & 4,10 & 0,400 \\
Kemudahan Memperoleh & 4,07 & 0,110 & 4,03 & 0,444 \\
\hline Total & 36,93 & 1,000 & 35,07 & 3,467 \\
\hline \multicolumn{4}{c}{ CSI = (WS : 5) x 100\% } \\
\hline
\end{tabular}

Sumber: Data Primer, 2015

Berdasarkan tabel di atas, jumlah atau total WS (Weighted Score) sebesar 3,467 . Weighted score per atribut diperoleh dari Rata-rata skor kepuasan per atribut di kalikan dengan Weighting Factor (WF) per atribut, sedangkan nilai atau angka perhitungan CSI sebesar 0,6934 atau 69,34\%. Nilai CSI produk es teh waralaba Teh 
cap Poci ini berada pada rentang 0,61 - 0,80 yang artinya indeks kepuasan memenuhi kriteria puas. Berikut tabel rentang skala.

Tabel 4.

Rentang Skala dan InterprestasiAnalisis Costumer Satisfaction Index

(CSI) Keseluruhan.

\begin{tabular}{cc}
\hline Rentang skala & Interpretasi \\
\hline $0,00-0,20$ & Sangat Kecewa \\
$0,21-0,40$ & Kecewa \\
$0,41-0,60$ & Cukup Puas \\
$0,61-0,80$ & Puas \\
$0,81-1,00$ & Sangat Puas \\
\hline
\end{tabular}

Perusahaan Teh cap Poci dan para pengusaha waralaba tetap perlu meningkatkan kinerja agar kriteria indeks kepuasan konsumen produk es teh waralaba Teh cap Poci menjadi sangat puas yakni mencapai $100 \%$, atau 1,0 karena jika sebaliknya yaitu skor penilaian CSI justru menurun hingga di bawah skor 0,4 dengan kriteria kecewa atau bahkan sangat kecewa maka konsumen bisa saja meninggalkan produk waralaba es Teh cap Poci dan mencari produk lain yang sesuai keinginan dan dapat memenuhi kepuasan para konsumen.

\subsubsection{Matriks importance-performance}

Matrix ini terdiri dari empat kuadran : kuadran pertama terletak di sebelah kiri atas, kuadran kedua di sebelah kanan atas, kuadran ketiga di sebelah kiri bawah, dan kuadran keempat di sebelah kanan bawah. Matrix hasil penilaian responden terhadap atribut produk es teh waralaba Teh cap Poci dapat dilihat pada gambar dibawah ini :

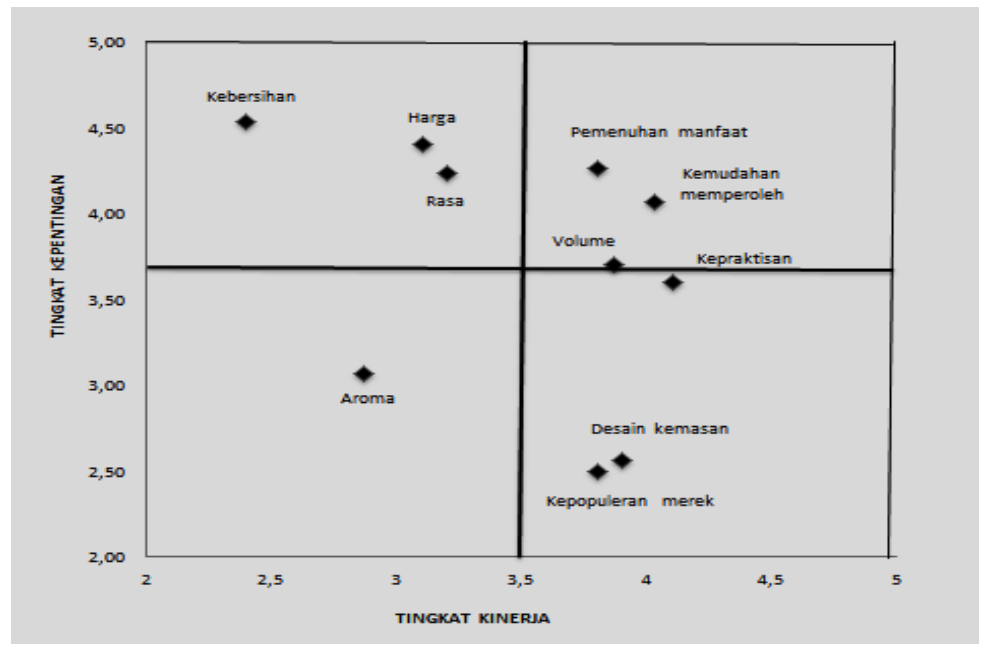

Gambar 1.

Matrix Importance Performance Analysis Produk Waralaba Teh cap Poci 
a. Prioritas Utama (Kuadran I). Menunjukkan faktor atau atribut yang dianggap mempengaruhi kepuasan pelanggan, termasuk unsur-unsur yang dianggap sangat penting, namun pengusaha belum melaksanakannya sesuai dengan keinginan pelanggan. Atribut kebersihan, harga, dan rasa merupakan atribut yang termasuk didalam kuadran ini sehingga perlu mendapat perhatian khusus baik bagi perusahaan atau pengusaha waralaba Teh cap Poci. Atribut kebersihan dapat ditingkatkan dengan cara menentukan berapa kali dalam sehari untuk membersihkan meja atu sekedar mengelap, serta mencuci alat-alat yang digunakan. Kebersihan penjual juga perlu diperhatikan, perlu disediakan sabun untuk mencuci tangan atau gel pembersih agar di gunakan sebelum membuat atau meracik es Teh cap Poci untuk konsumen. Atribut harga juga perlu mendapat perhatian pengusaha karena menurut konsumen yang mayoritas adalah kalangan menengah, bagi mereka harga es Teh cap Poci yang cukup tinggi. Oleh karena itu penentuan harga ini perlu diperhatikan, pengusaha dapat menghitung kembali biaya produksi agar harga ini dapat ditentukan dengan benar dan sesuai dengan keinginan konsumen, selain itu ada juga atribut rasa yang dianggap kurang memuaskan konsumen. Hal ini dikarenakan rasa es Teh cap Poci yang terkadang berubah-ubah dan juga rasa Teh cap Poci yang terkadang terlalu manis jika di campur dengan berbagai varian rasa. Perbaikan kinerja atribut rasa ini dapat dilakukan dengan memisahkan teh yang akan dijual original yang sudah memakai gula yang cukup dengan teh yang belum memakai gula atau sedikit gula yang akan dicampur dengan varian rasa, karena biasanya campuran varian rasa tersebut sudah mengandung gula.

b. Pertahankan Prestasi (Kuadran II). Menunjukkan faktor atau atribut yang telah berhasil dilaksanakan perusahaan, untuk itu wajib dipertahankannya. Dianggap sangat penting dan sangat memuaskan. Beberapa atribut yang berada pada kuadran ini yaitu : atribut pemenuhan manfaat, kemudahan memperoleh, dan volume. Atribut ini perlu dipertahankan kinerjanya adan ditingkatkan.

c. Prioritas Rendah (Kuadran III). Menunjukkan beberapa faktor yang kurang penting pengaruhnya bagi pelanggan, pelaksanaannya oleh perusahaan biasabiasa saja atau dianggap kurang penting dan kurang memuaskan. Satu-satunya atribut yang masuk dalam kuadran ini yaitu : atribut aroma. Atribut ini perlu mendapat perhatian dikemudian hari. Jika mengingat persaingan, karena akan ada pesaing yang dapat memenuhi keinginan konsumen akan aroma maka bisa saja konsumen akan berpindah ke produk pesaing tersebut.

d. Berlebihan (Kuadran IV). Menunjukkan faktor yang mempengaruhi pelanggan kurang penting, akan tetapi pelaksanaannya berlebihan atau dianggap kurang penting tetapi sangat memuaskan. Atribut yang berada pada kuadran ini adalah atribut desain kemasan,kepraktisan, dan kepopuleran merek. 


\section{Simpulan \\ 4.1 Simpulan}

Berdasarkan hasil dan pembahasan tersebut maka peneliti dapat menyimpulkan sebagai berikut:

1. Perhitungan CSI (customer satisfication index) atau tingkat kepuasan konsumen terhadap atribut produk waralaba Teh cap Poci di Kecamatan Denpasar Selatan yaitu dengan indeks kepuasan sebesar 69,34\% yakni memenuhi kriteria puas.

2. Berdasarkan Matriks Importance performance prioritas atribut yang akan dilakukan perbaikan yaitu pada kuadran I atribut kebersihan, harga, dan rasa merupakan atribut yang termasuk didalam kuadran ini sehingga perlu mendapat perhatian khusus baik bagi perusahaan atau pengusaha waralaba Teh cap Poci.

\section{Ucapan Terima Kasih}

Penulis mengucapkan banyak terimakasih kepada semua pihak yang telah membantu dalam pelaksanaan penelitian ini, terutama kepada kedua orang tua yang telah memberikan bantuan baik moril maupun materil dalam penyusunan e-jurnal ini sehingga dapat selesai tepat pada waktunya.

\section{Daftar Pustaka}

Arikunto, S. 2002. Prosedur Penelitian, Suatu Pendekatan Praktek. Jakarta: PT Rineka Cipta

Irawan, H. 2004. Kepuasan Pelanggan. Jakarta : PT. GramediaPustaka Utama.

Kotler, P. 1997. The Marketing of Nations, A Strategic Approach to Building National Wealth. New York: The Free Press.Jakarta.

Kotler, P. (2000). Marketing Management: Edisi Milenium, International Edition. Prentice HallInternational, Inc, New Jersey

Nawawi. 1997. Metode Penelitian Sosial. Jakarta: Rineka Cipta

Purwantini, A. 2014. Wow ! Perputaran Uang Bisnis Waralaba 2013 Di Indonesia Capai Rp. 214 Triliun. Internet [artikel on-line]. www.wartaharian.net/berita/2-ekonomi-keuangan-bisnis/7925-wow-

perputaran-waralaba-2013-di-indonesia-capai-rp-214-triliun.html (diunduh pada tanggal 18 april 2015)

Rangkuti, F. 2006. Measuring Customer Satisfaction. Jakarta : Gramedia Pustaka Utama.

Sugiyono. 2010. Metode Penelitian Pendidikan: Pendekatan Kualitatif Kuantitaifdan $R \& D$. Bandung : Alfabeta.

Sumarwan, U. 2004. Perilaku Konsumen. Bogor: Ghalia Indonesia

Supranto, J. 2006. Pengukuran Tingkat Kepuasan Pelanggan untuk MenaikkanPangsa Pasar, Cetakan Ketiga, Jakarta : PT.Rineka Cipta. 